See discussions, stats, and author profiles for this publication at: https://www.researchgate.net/publication/47636908

\title{
Phonological dyslexia without phonological impairment?
}

Article in Cognitive Neuropsychology · December 2004

DOI: 10.1080/02643290342000465 · Source: PubMed

CITATIONS

32

3 authors, including:

Michele Miozzo

Johns Hopkins University

83 PUBLICATIONS 3,271 CITATIONS

SEE PROFILE
READS

318
Yaakov Stern

Columbia University Vagalos College of Physicians and Surgeons 1,023 PUBLICATIONS 83,244 CITATIONS

SEE PROFILE

Some of the authors of this publication are also working on these related projects:

Predictive Modeling in Psychiatry and Neurology View project

Sign Language View project 


\title{
PHONOLOGICAL DYSLEXIA WITHOUT PHONOLOGICAL IMPAIRMENT?
}

\author{
Elise Caccappolo-van Vliet, Michele Miozzo, and Yaakov Stern \\ Columbia University, New York, USA
}

\begin{abstract}
RG, a patient with probable Alzheimer's disease, showed a severe impairment in nonword reading. RG's word reading was intact, for example, as demonstrated by her scores in standardised reading tasks, which were comparable to those of normal controls. No phonological impairment was apparent in speech production and comprehension. Moreover, RG performed well in a series of phonological tasks (e.g., production of a rhyming word, phoneme identification) on which patients with a reading deficit selective for nonwords have been reported to encounter problems. RG's data severely constrain reading models proposing that nonword reading deficits are caused by phonological deficits. However, RG's data are compatible with dual-route reading models, which do not propose a link between nonword reading deficits and phonological impairment.
\end{abstract}

Following focal brain lesions, not only may skilled readers encounter problems in word reading, but they may also exhibit problems reading certain types of words, as neuropsychologists have shown on a number of occasions (for a review, see Coltheart, Patterson, \& Marshall, 1987; Funnell, 2000; Rapp, Folk, \& Tainturier, 2000). Some patients have been reported as having markedly more difficulties in reading aloud irregular words than regular words, while their reading of novel letter strings (nonwords) was relatively spared, a pattern that is referred to as surface dyslexia. In languages like English or French, in which orthography allows only an imperfect realisation of phonology, patients with surface dyslexia fail more frequently with words that have an irregular orthography, such as the English words yacht or colonel. The opposite dissociation-an intact or relatively preserved ability to read words coupled with deficient nonword reading-has also been observed following brain damage, a dissociation that is referred to as phonological dyslexia. Word regularity plays little or no role in the word reading of phonological dyslexics, so that orthographically irregular words are pronounced as well as regular ones. Most of the errors that these patients produce with nonwords involve the substitution of a visually similar real word (e.g., taple $\rightarrow$ "table") or are the product of inappropriately applied grapheme-tophoneme conversion rules (e.g., stime pronounced as though it rhymed with Tim). Selective reading deficits like those documented in patients exhibiting surface or phonological dyslexia represent an important test case for models of reading and the debate over which model provides the most valid account of these deficits continues (Coltheart, 1996). In this paper we focus on phonological dyslexia and its implications for current reading models.

Correspondence should be addressed to Michele Miozzo, Department of Psychology, Columbia University, 1190 Amsterdam Avenue, New York, NY 10027, USA (Email: michele@psych.columbia.edu).

This work was supported by a National Institute of Aging grant, T32AG00261. Michele Miozzo was supported by a grant from the Keck Foundation. We thank patient RG and her family, and Jennifer Manly and Melissa Jacobs for their suggestions. 
So-called dual-route models offer a straightforward interpretation of selective nonword reading impairments (Berndt, Haendiges, Mitchum, \& Wayland, 1996; Coltheart, Curtis, Atkins, \& Haller, 1993; Marshall \& Newcombe, 1973). This class of models assumes two separate processing routes to derive the sound of written words (see Figure 1). Following the initial processing of the visual characteristics of a word, along one route a word's sound is retrieved from the lexicon by first accessing the representations that specify the orthography and the meaning of the word. The other route consists of mechanisms converting a grapheme or a group of graphemes into the corresponding phonemes so as to derive the pronunciation most typically associated with one or more graphemes. Supposedly, in this route phonology is not obtained by addressing stored word representations in an orthographic lexicon. In normal conditions, both routes are available for word reading; however, because nonwords lack semantic and phonological representations, only the nonlexical route can be used to derive the appropriate pronunciation of a nonword. Conditions in which the nonlexical route is selectively damaged are then supposed to lead to problems in reading nonwords. However, because the other "lexical" route is (relatively) intact, and because this route is

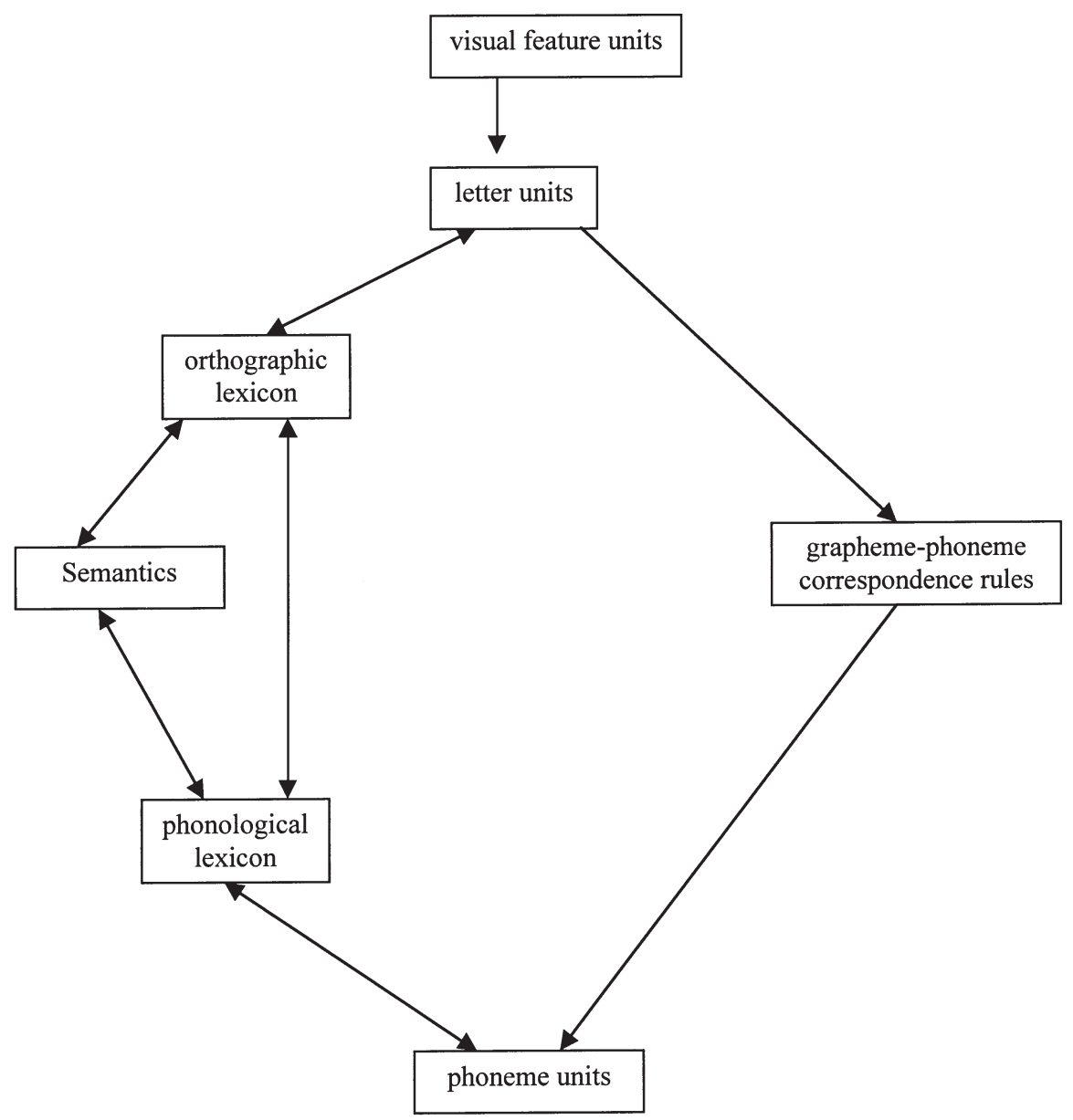

Figure 1. Dual-route model of word recognition (after Coltheart et al., 1993). 
critical for deriving the phonology of familiar words, reading of familiar words would remain (relatively) spared. Therefore, by assuming that a deficit selectively or more severely affects the nonlexical reading mechanisms, dual-route models can account for the pattern of deficits observed in phonological dyslexia. The nonlexical route is conceived as a bundle of mechanisms, and although the precise nature of these mechanisms is still a matter of debate, there seems to be agreement on one point: individual mechanisms can be compromised to different degrees in conditions of brain damage and so give rise to different forms of nonword reading deficits (for a discussion of this point see, e.g., Berndt et al., 1996; Derouesné \& Beauvois, 1985).

The notion, central in dual-route models, that separate mechanisms are implicated in reading words and nonwords which, if damaged, determine selective deficits in reading either words or nonwords, has not gone unchallenged. As an alternative, in various connectionist models of reading it is proposed that the same mechanisms underlie the processing of words and nonwords. A type of model implementing this view is the socalled triangle model, of which different versions have been developed (e.g., Harm \& Seidenberg, 1999; Plaut, McClelland, Seidenberg, \& Patterson, 1996; Seidenberg \& McClelland, 1989). A schematic illustration of the model proposed by Seidenberg and McClelland is shown in Figure 2. In this model, activation coming from both the orthographic and the semantic units determines the selection of the phonological units corresponding to a given letter string. Crucially, in this model there are no mechanisms specifically devoted to the retrieval of nonword phonology. This model holds that nonword phonology is processed by the same mechanisms involved in word reading. In a model of this type, impairment at the phonological level is assumed to be the cause of deficits that would affect nonword reading more severely (Harm \&

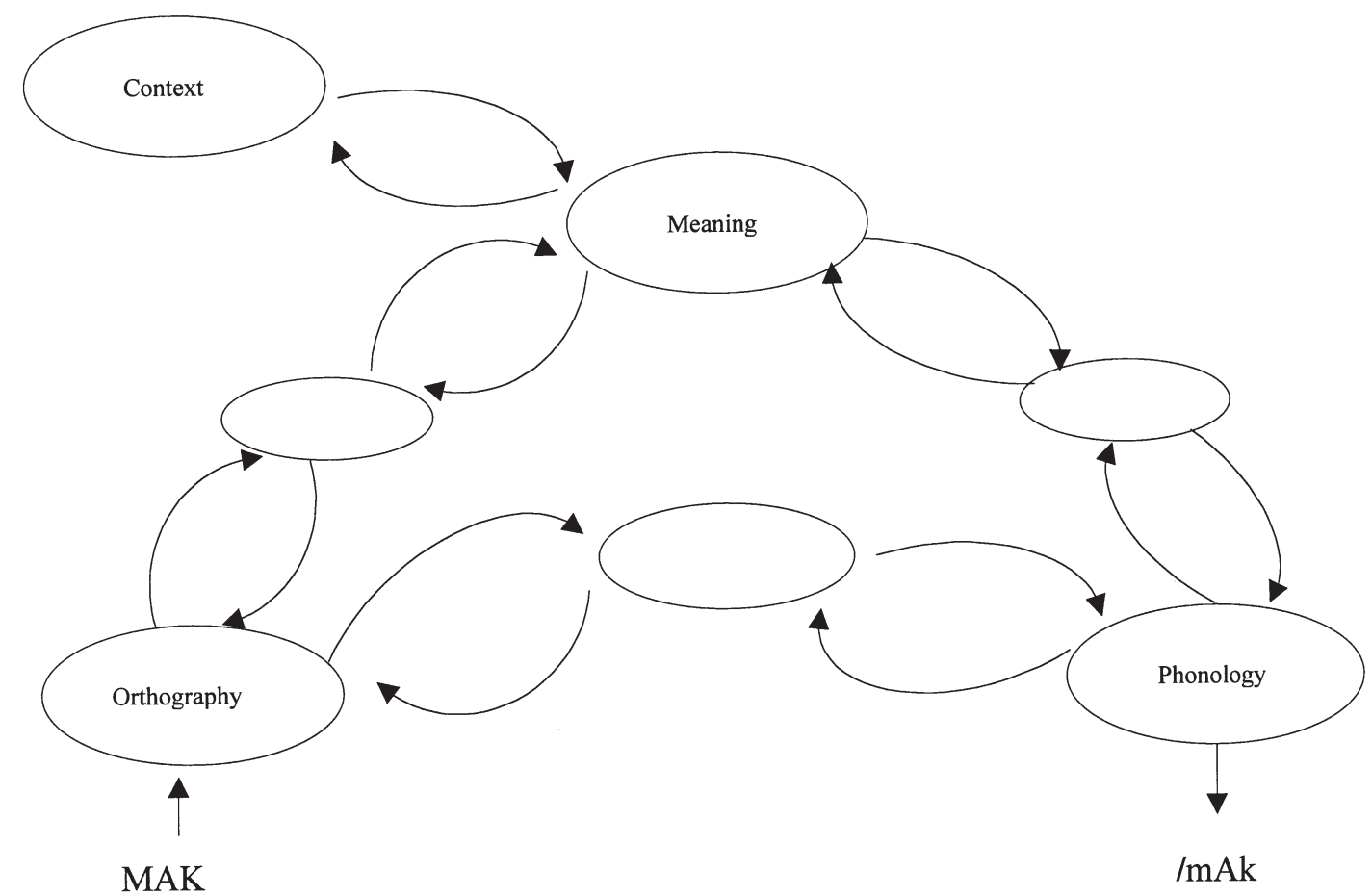

Figure 2. Seidenberg and McClelland's (1989) "triangle" model of reading. 
Seidenberg, 2001; Patterson \& Lambon Ralph, 1999). We refer to this account as the phonological impairment account. This account stems from the hypothesis that nonwords have less stable phonological representations than words, a fact that renders nonwords more vulnerable to damage at the phonological level. A variety of reasons have been proposed as to why phonological representations are less stable for nonwords than they are for words (Harm \& Seidenberg, 2001): nonwords are inherently less familiar; nonwords do not strongly activate the semantic system (and thereby do not receive strong activation from it); and nonwords do not have established connections between orthography and semantics (as familiar words have), which can further contribute to the activation of phonology. Together, these factors yield less stable representations for nonwords, which in turn exposes nonword reading to more severe deficits when phonology is damaged.

Farah, Stowe, and Levinson (1996) also entertained the hypothesis that selective impairments for nonwords, such as those observed in phonological dyslexia, arise as a consequence of a phonological deficit, although their hypothesis stems from a different theoretical perspective. The starting point of their hypothesis is that reading differs from other cognitive functions, such as visual object recognition and oral naming, because it is the product of instructional training, typically training that is extensive and formally structured, and takes place at a relatively late age. Also, from an evolutionary perspective, reading is a recently acquired skill. According to Farah et al. (but see also Farah, 1992), only cognitive systems that are innate or mature at an early age, and have a long evolutionary history, are supposed to have dedicated brain structures. Obviously, this should not hold for reading, which must piggyback on already developed brain structures, originally dedicated to other cognitive functions: vision and phonology. Within this framework, there is no room for a deficit that selectively affects reading; rather, a reading impairment should always be accompanied either by a visual or a phonological deficit. In line with the arguments discussed above in the context of the connectionist models, Farah et al. advanced the hypothesis that a phonological deficit would affect the reading of nonwords more severely than the reading of words, and so explained the dissociation observed in phonological dyslexia.

The explanation proposed for nonword reading deficits by the phonological impairment account and the explanation derived from the dual-route models differ in two crucial respects. Only dualroute models assume the existence of mechanisms dedicated to nonword reading. However, only the phonological impairment account predicts that impaired nonword reading should appear in the context of a more general phonological deficit. Whether there are phonological dyslexic patients who do not show signs of a more general phonological impairment is, then, a crucial test for the current accounts of phonological dyslexia and for constraining hypotheses about the existence of mechanisms selectively devoted to the processing of nonwords.

When we examine the fairly large number of patients tested thus far, it seems almost the norm that selective or more severe reading deficits for nonwords are accompanied by a phonological deficit $^{1}$ (Coltheart, 1996; Harm \& Seidenberg, 2001; Patterson, 2000). But exceptions to this pattern have also been reported, though much more rarely: To date, we know of only two "discordant" cases. One is patient LB, described by Derouesné and Beauvois (1985), whose phonological processing was assessed by means of tasks that

\footnotetext{
${ }^{1}$ While these cases are consistent with the phonological impairment hypothesis, they can also be explained within the framework of dual-route mechanisms. One possibility is to assume that mechanisms for nonword reading are represented by neuroanatomical structures contiguous to those subserving phonological processing. Both areas are likely to be damaged by the vast brain lesions that are typically observed in neuropsychological patients. That is, the co-occurrence of deficits reported in these patients is more a neuroanatomical accident rather than the consequence of functional organisation. Dissociations between nonword reading and phonological processing are more important in this respect, because they help us to discriminate between the current alternative reading models.
} 
required various forms of phoneme manipulations. For example, in one task LB was presented with three phonemes $(/ \mathrm{g} /, / \mathrm{r} /, / \mathrm{a} /)$ and was asked to pronounce the corresponding syllable (/gra/); in another task LB pronounced the last phoneme of the word spoken by the experimenter. LB performed very well in all these tasks, leading Derouesné and Beauvois to conclude that their patient was not phonologically impaired. The second patient with reading problems confined to nonwords without signs of a phonological deficit was RR, reported by Bisiacchi, Cipolotti, and Denes (1989). For example, RR was always able to pronounce the first phoneme of an aurally presented word, and even in the very difficult spoonerising task, which requires swapping word onsets (as in John Lennon $\rightarrow$ "Lohn Jennon"), RR's performance was comparable to that of normal controls (correct: $18 / 20$ vs. 19.2/20). The putative absence of a phonological deficit in patients LB and $\mathrm{RR}$ is problematic for the phonological impairment hypothesis, whereas it is consistent with dual-route models, which do not posit any association between deficits for nonword reading and for phonological processing.

But the results obtained from patients LB and RR have also been criticised on several grounds. Patterson (2000) pointed out that LB's word reading accuracy, while not normal-it ranged between $74 \%$ and $98 \%$ correct-was not far from the accuracy levels observed with nonwords, which ranged between $48 \%$ and $85 \%$ correct. It becomes debatable whether LB exhibits a strong dissociation between words and nonwords in reading and consequently whether inferences about the effects of selective impairments of nonword reading can be made on the basis of this case. Similar conclusions were reached by Patterson for patient RR, as there were indications that this patient could read short nonwords but had some problems with lowfrequency abstract familiar words. Moreover, Harm and Seidenberg (2001) discussed the possibility that LB's relatively good performance in the phonological tasks resulted from rehabilitation training that focused on phonological reading and improved the patient's performance in the phonological tasks without ameliorating nonword reading. Finally, Harm and Seidenberg pointed out that in some phonological tasks in which LB did not score perfectly ( $85 \%$ and $90 \%$ correct), normal controls are likely to perform at ceiling. Perhaps it is fair to describe LB's performance in phonological tasks as mildly impaired. But when compared with other patients, it is arguable that LB's performance in nonword reading is also mildly impaired. That is, one may question if phonological processing is in fact preserved in LB, as it seems that phonological processing and nonword reading are qualitatively similar in this patient.

In light of the remarks raised about the two cases cited as examples of intact phonological processing in phonological dyslexia, it becomes even more crucial to determine the extent to which phonological deficits and phonological dyslexia are dissociable. The data of $\mathrm{RG}$, a patient with probable Alzheimer's Disease (pAD) documented in the present paper, address these issues. RG has significant difficulties in reading nonwords; remarkably, her word reading appears to be intact, as demonstrated by her performance on standardised tests. Thus, our patient escapes some of the criticisms raised for other cases and provides a good opportunity to further examine the intactness of phonological processing. The examination of a patient with moderate $\mathrm{pAD}$ represents a departure from previous case studies of phonological dyslexia, whose brain damage resulted from CVAs. But reading deficits have been recorded in a number of studies that assessed the cognitive deficits associated with pAD (e.g., Cummings, Houlihan, \& Hill, 1986; Graham, Hodges, \& Patterson, 1994). $\mathrm{RG}$, like other $\mathrm{pAD}$ patients at a comparable stage of cognitive decline, presents with additional impairments that severely limit the possibility of comprehending and completing relatively complex tasks. These additional impairments restrict the types of tests that can be administered for assessing phonological abilities. RG was unable to comprehend the instructions for some of the tests, which therefore had to be discontinued in favour of simpler ones. Despite these limitations, the pattern of results demonstrates intact phonological ability.

The presentation of RG's data is organised as follows. First, we introduce the case by tracing the 
progress of RG's dementia. The following section is devoted to establishing how accurately RG can process words and nonwords. Finally, we examine the data from tasks relevant for assessing RG's phonological processing.

\section{CASE REPORT}

$\mathrm{RG}$ is a 72-year-old, right-handed woman with 13 years of education. She worked part-time as a clerk until retiring, and was also heavily involved in managing her household. She began experiencing memory problems in 1992, at which time she sought the opinion of the first of many neurological specialists. A neuropsychological evaluation from 1995 indicated severely impaired immediate and recent memory, with mild to moderate impairment in other cognitive functions including attention, concentration, abstraction, sequential reasoning, organising, and planning. An MRI scan carried out in 1995 revealed no abnormalities. Follow-up neuropsychological testing from 1996 led to a diagnosis of probable Alzheimer's Disease.

Starting in 1997, RG's cognitive deficit has been periodically evaluated at the Memory Disorders Center of Columbia Presbyterian Medical Center. The neuropsychological testing administered in 1997 revealed significant deficits in orientation and long- and short-term memory (see Table 1), which

Table 1. Neuropsychological tests: $R G$ 's scores over three evalutions

\begin{tabular}{|c|c|c|c|c|c|c|}
\hline \multirow[b]{2}{*}{ Neuropsychological tests } & \multirow[b]{2}{*}{ Range } & \multicolumn{2}{|c|}{ Controls $^{a}$} & \multicolumn{3}{|c|}{$R G$ 's scores } \\
\hline & & Mean & $(S D)$ & 1997 & 1999 & 2001 \\
\hline \multicolumn{7}{|l|}{ Orientation } \\
\hline Modified Mini Mental Status Exam & $0-57$ & 52 & (3) & 40 & 31 & 23 \\
\hline \multicolumn{7}{|l|}{ Attention } \\
\hline Cancellation Test & $0-240$ & 63 & $(27)$ & 87 & 112 & $\mathrm{NC}^{\mathrm{b}}$ \\
\hline \multicolumn{7}{|l|}{ Construction } \\
\hline Rosen Drawing Test & $0-5$ & 3 & (1) & 5 & 3 & 2 \\
\hline Benton Visual Retention Test: Matching & $0-10$ & 9 & (1) & 9 & 8 & $\mathrm{NC}^{\mathrm{b}}$ \\
\hline \multicolumn{7}{|l|}{ Memory } \\
\hline \multicolumn{7}{|l|}{ Selective Reminding Test } \\
\hline Total recall & $0-72$ & 43 & (9) & 13 & 18 & 11 \\
\hline Delayed recall & $0-12$ & 6 & (3) & 0 & 0 & 0 \\
\hline Delayed recognition & $0-12$ & 11 & (1) & $\mathrm{NC}^{\mathrm{b}}$ & 7 & 1 \\
\hline Benton Visual Retention Test: Recognition & $0-10$ & 8 & (2) & 7 & 2 & $\mathrm{NC}^{\mathrm{b}}$ \\
\hline \multicolumn{7}{|l|}{ Verbal short-term memory } \\
\hline Digit span (WAIS-R) & $1-19$ & 10 & (3) & 5 & $\mathrm{NA}^{\mathrm{c}}$ & 3 \\
\hline \multicolumn{7}{|l|}{ Language } \\
\hline Boston Naming Test & $0-15$ & 14 & (1) & 15 & 15 & 14 \\
\hline Controlled word association (CFL) & 0-100th \%ile & 64 & $(31)$ & 80 & 34 & 1 \\
\hline Category fluency (Animals) & 0-100th \%ile & 36 & $(28)$ & 18 & 1 & 2 \\
\hline Sentence repetition (BDAE) & $0-8$ & 7 & (1) & 8 & 7 & 4 \\
\hline Comprehension (BDAE) & $0-6$ & 6 & (1) & 5 & 4 & 3 \\
\hline \multicolumn{7}{|l|}{ Abstract reasoning } \\
\hline Similarities (WAIS-R) & $0-20$ & 11 & (3) & $\mathrm{NA}^{\mathrm{c}}$ & 10 & 7 \\
\hline Identities \& oddities (Mattis RS) & $0-16$ & 15 & (1) & 15 & 14 & 6 \\
\hline
\end{tabular}

${ }^{a}$ Nondemented elderly $(N=155)$.

${ }^{\mathrm{b}} \mathrm{NC}=$ not completed: the patient was unable to complete the test.

${ }^{\mathrm{c}} \mathrm{NA}=$ not administered . 
have become increasingly severe as the disease progresses. In the most recent follow-up evaluation (January, 2001), abstract reasoning, attention, and language comprehension also appeared to be severely impaired and her score on a modified version of the Mini-Mental Status Examination (mMMSE; Mayeux, Stern, Rosen, \& Leventhal, 1981) dropped to 23/57, indicating moderate dementia. Of note is the fact that she was unable to complete some of the tests that were re-administered to her at this time. RG probably did not comprehend the instructions of these tasks, a common finding among moderate dementia patients who are often untestable due to impaired working memory and rapid forgetting of information (Butters et al., 1988; Welsh, Butters, Hughes, Mohs, \& Heyman, 1991). A MRI scan carried out in 2000 was notable for mild cerebral atrophy with atrophic hydrocephalus compatible with age. At the time of the present investigation, the behavioural manifestations of RG's dementia were significant. For example, she cannot go out unaccompanied because she gets lost even in familiar environments. Episodes in which she had just returned from walking the dog with her husband and then inquired whether the dog should be walked occurred frequently, as well as those in which she lost track of the task at hand.

Remarkably, oral picture naming remained the only preserved cognitive domain in patient $\mathrm{RG}$, as can be seen in Table 1 . In a modified version of the Boston Naming Test, the patient identified the same number of pictures as controls (14/15), a striking finding that suggested intact phonological processing, and which prompted the detailed investigation of RG's reading and phonological processing reported below. This investigation was initiated in January 2001, immediately following the third follow-up neuropsychological testing, and continued for 8 months. During this period RG's cognitive and functional abilities remained relatively stable, as demonstrated by her identical scores $(23 / 52)$ on the mMMSE at the beginning and the end of the present investigation. In all testing sessions, both reading and phonological tasks were administered so as to avoid a confounding between time of testing and task. At the time of our investigation RG's spelling was impaired. Her handwriting was not completely intelligible, thus we only tested oral spelling; RG had problems with words (75/103 correct; 73\%) as well with nonwords (2/23 correct; $8.6 \%)$. Nonword testing in spelling was discontinued because the patient found the task frustrating. ${ }^{2}$

\section{READING PROCESSING}

\section{Reading aloud: Words}

The objective of the word reading aloud task was twofold. On one hand, we wanted to accurately evaluate the intactness of RG's word reading, and this end we administered two standardised reading tests; the Wide Range Achievement TestR (WRAT-R; Jastak \& Wilkinson, 1984) and the Nelson Adult Reading Test (NART; Grober \& Sliwinski, 1991). On the other hand, we wanted to determine whether RG had problems in reading function words and words that were morphologically complex, as observed in some of the reported patients with phonological dyslexia (e.g., Friedman, 1996). To obtain as thorough a picture as possible, we also determined whether RG's accuracy varies as a function of other variables known to affect reading (e.g., frequency and regularity).

Over various testing sessions, RG was asked to read aloud 1404 words. Words were presented at

\footnotetext{
${ }^{2}$ Phonological processes that allow for the segmentation of phoneme sequences and for the recognition of the individual phonemes are critical for correctly spelling nonwords presented in dictation tasks. It would be interesting to examine whether RG's impairment for nonword spelling stems from a phonolgical deficit, and whether such a deficit is also responsible for RG's problems in nonword reading. Unfortunately, we were unable to pursue these questions with patient RG.
} 
the centre of $8.5 \times 11$ " paper sheets, approximately 15 per page, and were printed in lower-case, 20point Times font. With a few exceptions, words were presented along with nonwords. The patient was informed that some of the items were nonexisting words and examples were provided. RG was encouraged to read the words at her own pace and she was allowed unlimited time to respond. In the case of multiple responses, her last response was scored. (We arrived at essentially the same results when first responses were scored.)

RG performed well within normal limits for her age and education level on each of the standardised tests we administered, as can be seen from the data summarized in Table 2. For example, RG's gradeequivalent score on the WRAT-R (31/42 correct) was equivalent to high school (RG's actual education level) and corresponds to the 57th percentile. On the NART, RG performed better than pAD patients. Previous studies have reported that $\mathrm{pAD}$ patients perform poorly in this test as compared to normal elderly controls (Cummings et al., 1986; Fromm, Holland, Nebes, \& Oakley, 1991). These standardised tests included fairly unfamiliar words like regime, longevity, and mitosis, which RG named successfully, thereby showing remarkably intact word reading ability.

Other word lists were administered to determine whether spelling-to-sound regularity affects $\mathrm{RG}$ 's reading. These lists have been used in prior studies (Coltheart, Besner, Jonasson, \& Davelaar, 1979; Glushko, 1979; Shallice, Warrington, \& McCarthy, 1983) and were composed of regular words (e.g., market, save) and irregular words (e.g., yacht, comb) matched on a series of other parameters (e.g., frequency, number of letters/syllables, number of neighbours). No difference emerged between regular and irregular words in any of these lists $\left(\chi^{2} s<1\right.$; see data in Table 2$)$, and overall $R G$ was correct with $99 \%$ of the regular words (162/ $163)$ and $97 \%$ of the irregular words (158/163). The extent to which concreteness, grammatical class, frequency, regularity, and word length affect RG's reading accuracy was tested by means of the Johns Hopkins Dyslexia Battery (Goodman \& Caramazza, 1986), which includes sets of words varying in each of these variables. The data,
Table 2. Word reading aloud tests

\begin{tabular}{|c|c|c|}
\hline Test & \multicolumn{2}{|c|}{$R G$ 's correct responses } \\
\hline \multicolumn{3}{|l|}{ Standardised test } \\
\hline WRAT-R & \multicolumn{2}{|c|}{ 31/42 (57th \%ile) } \\
\hline NART & \multicolumn{2}{|c|}{ 31/45 (81st \%ile) } \\
\hline Word regularity/list & $\begin{array}{c}\text { Regular } \\
\text { words }\end{array}$ & $\begin{array}{c}\text { Irregular } \\
\text { words }\end{array}$ \\
\hline Coltheart et al. (1979) & $39 / 39(100 \%)$ & $38 / 39(97 \%)$ \\
\hline Glushko (1970) & $43 / 43(100 \%)$ & $42 / 43(97 \%)$ \\
\hline Glushko (1970) & $41 / 41(100 \%)$ & $40 / 41(97 \%)$ \\
\hline Shallice et al. (1983) & $39 / 40(97 \%)$ & $38 / 40(95 \%)$ \\
\hline \multicolumn{3}{|l|}{ Johns Hopkins Dyslexia } \\
\hline \multicolumn{3}{|l|}{ Battery } \\
\hline \multicolumn{3}{|l|}{ Concreteness } \\
\hline Concrete & \multicolumn{2}{|c|}{$20 / 20(100 \%)$} \\
\hline Abstract & \multicolumn{2}{|c|}{$20 / 20(100 \%)$} \\
\hline \multicolumn{3}{|l|}{ Part of speech } \\
\hline Nouns & $25 / 26$ & $(96 \%)$ \\
\hline Verbs & $25 / 26$ & $(96 \%)$ \\
\hline Adjectives & $25 / 26$ & $(96 \%)$ \\
\hline Functors & $25 / 26$ & $(96 \%)$ \\
\hline \multicolumn{3}{|l|}{ Regularity } \\
\hline Regular & $35 / 36$ & $(97 \%)$ \\
\hline Irregular & $36 / 36$ & 100\%) \\
\hline \multicolumn{3}{|l|}{ Frequency } \\
\hline Concrete & \multicolumn{2}{|c|}{$25 / 25(100 \%)$} \\
\hline Abstract & \multicolumn{2}{|c|}{$25 / 25(100 \%)$} \\
\hline \multicolumn{3}{|l|}{ Word length } \\
\hline 4 letters & \multicolumn{2}{|c|}{$15 / 15(100 \%)$} \\
\hline 5 letters & \multicolumn{2}{|c|}{$15 / 15(100 \%)$} \\
\hline 6 letters & \multicolumn{2}{|c|}{$15 / 15(100 \%)$} \\
\hline 7 letters & \multicolumn{2}{|c|}{$15 / 15(100 \%)$} \\
\hline 8 letters & \multicolumn{2}{|c|}{$14 / 15 \quad(93 \%)$} \\
\hline \multicolumn{3}{|c|}{ Morphological complexity } \\
\hline Prefixed words & \multicolumn{2}{|c|}{$74 / 75 \quad(98 \%)$} \\
\hline Controls & \multicolumn{2}{|c|}{$75 / 75(100 \%)$} \\
\hline Inflected words & \multicolumn{2}{|c|}{$74 / 75 \quad(98 \%)$} \\
\hline Controls & \multicolumn{2}{|c|}{$74 / 75 \quad(98 \%)$} \\
\hline Compounds & \multicolumn{2}{|c|}{$75 / 75(100 \%)$} \\
\hline Controls & \multicolumn{2}{|c|}{$74 / 75 \quad(98 \%)$} \\
\hline
\end{tabular}

summarised in Table 2, reveal that RG's reading accuracy is not affected by any of these variables $\left(\chi^{2} \mathrm{~s}\right.$ $<1)$. Other word lists from Badecker, Hillis, and Caramazza (1990) were administered to examine whether RG, like some other patients with phonological dyslexia, encounters difficulties in naming multimorphemic words. These lists included prefixed words (unpack), inflected words (towels), 
and compounds (starfish). Each multimorphemic word was paired with a monomorphemic word roughly matched for frequency and number of letters. The number of correctly named words was identical between the two groups of items (223/ 225, 99\%). No significant difference was observed between derived words composed of productive suffixes (e.g., -ness, as in sadness, -er, as in traveler) and those composed of nonproductive suffixes (e.g., -ion, as in reduction, -al, as in seasonal; lists from Badecker et al., 1990); the number of correct responses were $74 / 75$ and $75 / 75$, respectively. A final list was composed of words that were used to derive some of the nonwords administered to the patient; accuracy was also very high with these words (49/50; 98\%).

To summarise, RG correctly read 97\% (1361/ 1404) of all the words presented to her. RG's performance in the word reading aloud task is indistinguishable from that of normal controls with a comparable level of education. There was no effect of variables known to affect the performance of patients with surface dyslexia or the performance of some of the patients with phonological dyslexia, including regularity, concreteness, part of speech, and morphological complexity. Many of the words RG was able to read included multisyllabic, irregular words such as façade, catastrophe, and regime, which are often difficult for most people, let alone for $\mathrm{PAD}$ patients. And as for normal controls, RG's few errors occurred with words that are infrequent according to Francis and Kucera's (1982) norms ( mean $=4$ counts per million words, range $=0-47$; the only exception was the error with the highfrequency word been).

\section{Reading comprehension}

While the results presented thus far have defined the extent to which RG derives the sound of written words, other tasks addressed the parallel issue of how RG accesses their meaning. Scores as low as those obtained by RG in the category fluency task or in the controlled oral word association (CFL) tasks (see Table 1) are frequently observed among patients with moderate dementia and are commonly interpreted as reflecting impaired semantic processing (e.g., Monsch, Bondi, Butters, Salmon, Katzman, \& Thal, 1992). Consistent with this interpretation, it is very likely that RG's reading comprehension would not be normal. The question, however, is whether the comprehension of written words would be more impaired than the comprehension of words presented in the oral modality, indicating a specific deficit in accessing the meaning of written words. We therefore asked RG to perform a word-picture matching task (from the BORB, Riddoch \& Humphreys, 1993) twice, once with written words and once with orally presented words. In both conditions, the patient was asked to indicate which of the two pictures was more related to a probe word. Examples include the triplet pyramid (the probe), camel (the target), and bear (the foil), and the triplet nail (the probe), pliers (the target), and chisel (the foil). As evident from these examples, access to detailed semantic representations is required to respond correctly in this task. RG's score with orally presented words was within controls' range $(25 / 30,83 \% ; z=-1.04)$. A similar score $27 / 30$ (90\%) was found with written words. This finding rules out a problem of semantic access that is specific for written words. This conclusion is further supported by the results of a second task (Miozzo \& Barnes, 2002), in which $\mathrm{RG}$ was asked to indicate which word in a pair refers to an animal. The target and the foil were visually similar and differed by one letter (as in dogfog) or by two letters (as in as in clam-clack). She successfully identified 48/50 words; the missed targets were yak and fowl (instead she chose yam and fool), perhaps because these words referred to concepts that were not familiar to her.

\section{Reading aloud: Nonwords}

RG's nonword reading was evaluated with a standardised test (Word Attack subtest of the Woodcock Johnson Battery, 1991) and lists that were used in previous studies (Berndt et al., 1996; Friedman, Ferguson, \& Robinson, 1992; Glushko, 1979; Kay \& Patterson, 1985) or that we had developed specifically for the patient. The nonwords of the various lists were monosyllabic and 3-5 letters in length, with the exception of the nonwords of the 
Word Attack list (2-10 letters) and of our list (4-6 letters). The items in our list and those from Glushko and Kay and Patterson were obtained by changing a letter to an existing word, as in beef $\rightarrow$ heef. Nonwords from Word Attack and Friedman et al. were presented alone whereas nonwords from the remaining lists were shown with familiar words in a 1:1 ratio. In total $\mathrm{RG}$ was shown 564 nonwords. $\mathrm{RG}$ was instructed to read the nonwords as best she could, and was told that there was no right or wrong answer. As we mentioned earlier, the patient was informed that lists comprised both words and nonwords, which appeared in random order. A response was scored as correct if it conformed to rules of English pronunciation (Venezky, 1970) or to pronunciations of real English words with irregular spellings (e.g., heaf read as rhyming with deaf). Note that this scoring procedure would inflate the number of correct responses.

Overall, RG correctly pronounced only 307/564 (54\%) nonwords and her performance was consistently poor across reading lists, as mean correct response rates on these lists ranged between $40 \%$ and 68\% (see summary in Table 3). The list from Berndt et al. (1996) consisted of monosyllabic letter strings that have one highly probable grapheme-

Table 3. Nonword reading aloud tests

\begin{tabular}{lrl}
\hline Test & $R G^{\prime}$ 's plausible responses \\
\hline Woodcock-Johnson (Word Attack) & $15 / 28 \quad(53 \%)$ \\
Friedman et al. (1992) & $54 / 121(45 \%)$ \\
Glushko (1979) & $82 / 138(59 \%)$ \\
Kay and Patterson (1985) & $32 / 80 \quad(40 \%)$ \\
Berndt et al. (1996) & & \\
High GPC & $22 / 33 \quad(67 \%)$ \\
Low GPC & $4 / 20 \quad(20 \%)$ \\
Total & $26 / 53 \quad(49 \%)$ \\
Length list & & \\
4-letters & $36 / 48 \quad(75 \%)$ \\
5-letters & $27 / 48 \quad(56 \%)$ \\
6-letters & $35 / 48 \quad(73 \%)$ \\
Total & $98 / 144(68 \%)$ \\
\hline
\end{tabular}

phoneme correspondence (GPC), like neep and vit, and monosyllabic letter strings not corresponding to a single, highly probable pronunciation, like gach and woth. GPC affected RG's responses, which were more accurate with high GPC words $(22 / 33$, $67 \%)$ than with low GPC words (4/20, 20\%); $\chi^{2}(1)$ $=9.06, p<.01$; Yates' correction applied. This discrepancy could have arisen because lowfrequency GPC rules are more susceptible to error than high GPC rules or because RG attempted to retrieve the pronunciation on the basis of existing words, an approach that is more likely to lead to the correct answer when a single pronunciation is retrieved from the lexicon. Whatever the explanation, it is interesting to note that the same GPC effect was observed by Berndt et al. only in patients who, like RG, were good ( $\geq 90 \%)$ at word reading.

Further data showed that RG's responses to nonwords were affected not only by whether the nonwords were visually similar to familiar words but also by the orthography of these familiar words. The lists of Glushko (1979) and Kay and Patterson (1985) included nonwords derived from visually similar word sets with either consistent pronunciation (e.g., leap, heap, reap, etc.) or inconsistent pronunciation (as in bearlfear). RG was less accurate with nonwords similar to "consistent" than "inconsistent" word sets (data combined from the two lists: $49 / 109,45 \%$ vs. $65 / 109,60 \%) ; \chi^{2}(1)=$ 4.7, $p=.03$. This difference in part reflects an asymmetry in lexicalisation errors, i.e., responses in which RG produced a visually and phonologically similar word, as in woog $\rightarrow$ "wood." Lexicalisations tended to be more common with nonwords having "consistent" than "inconsistent" neighbours (Nlexicalisations/N errors: 48/60, 80\% vs. $28 / 44,64 \%) ; \chi^{2}(1)=3.4, p=.06$.

Like other patients with phonological dyslexia, the majority of RG's errors (71\%) were represented by lexicalisations. Of the remaining errors, $18 \%$ were nonwords that contained at least $50 \%$ of the phonemes in the target letter strings (e.g., fent $\rightarrow$ "fenk"), 9\% were nonwords containing one or more additional phonemes (e.g., teus $\rightarrow$ "saseus"), and $2 \%$ were nonword responses that had fewer than 50\% of the phonemes of the target item (e.g., feep $\rightarrow$ "fick").

COGNITIVE NEUROPSYCHOLOGY, 2004, 21 (8) 
One may suspect that RG's poor performance with nonwords is the result of presenting nonwords in lists that also contained words. Perhaps the patient formed the impression that there was an excessive number of words and so attempted to read many of the items as familiar words. This approach would explain not only the low accuracy rate for nonwords but also the high incidence of lexicalisations. However, there are data that rule out this type of account. The correct rate for nonwords presented alone (Woodcock-Johnson subtest: 54\%; Friedman et al.'s, 1992, lists 45\%) was comparable to that of nonwords shown in mixed lists also comprising words (57\%). Moreover, the occurrence of lexicalisation errors was not higher in mixed lists $(118 / 177 ; 66 \%)$ than in nonword lists $(64 / 80$; $80 \%)$. We should further note that the proportions of lexicalisations ranged between $35 \%$ and $67 \%$ in a group of 11 individuals with acquired phonological dyslexia presented with lists only composed of nonwords (Berndt et al., 1996). When the same nonwords were shown to RG in a mixed list, her proportion of lexicalisation errors was comparable at $59 \%$.

\section{IS OUTPUT PHONOLOGICAL PROCESSING INTACT?}

The reading tests revealed a stark dissociation: While RG's ability to read nonwords was severely impaired, her ability to read words, even unfamiliar words and those words with an irregular spelling, appeared to be intact. This pattern, characteristic of phonological dyslexia, can only be attributed to deficient phonological processing in reading models that appeal to the phonological impairment hypothesis. According to this hypothesis, RG should also be impaired in tasks requiring phonology but that are without an orthographic component. To investigate this prediction, we tested RG with phonological tasks developed in previous studies of phonological dyslexia, in addition to devising new tasks. Due to RG's difficulty in following complex instructions, we had to provide simpler versions of many of the tasks administered to other patients with acquired phonological dyslexia. Even so, RG often forgot the task at hand and required multiple repetitions of the instructions. Nonetheless, her performance on the following tests indicates intact phonological ability.

\section{Language production}

The type of deficit assumed by the phonological impairment hypothesis should not be confined to nonword reading; instead, it should extend to other tasks that implicate phonological processing. Speaking is one such task and we therefore evaluated the extent to which phonological processes were intact in RG's speaking. We were specifically interested in screening for a variety of error types observed in aphasic patients with impaired phonological processing in speech production (Blumstein, 1981), including the substitution of one or more phonemes (as in book $\rightarrow$ "dook"), their omission (as in tree $\rightarrow$ "tee") or addition (as in pen $\rightarrow$ "plen"). RG was asked to name a total of 170 pictures from various sources (Boston Naming Test: Kaplan, Goodglass, \& Weintraub, 1983; Philadelphia Naming Test: Roach, Schwartz, Martin, Grewal, \& Brecher, 1996; Snodgrass Test: Snodgrass \& Vanderwart, 1980). RG was able to name a good portion of these pictures (155/170, 91\%) and her performance was within normal limits for her age group on the Boston Naming Test (50/60 correct; $35^{\text {th }}$ percentile). Of particular interest here are the types of errors committed by $\mathrm{RG}$ in picture naming. Among her errors, which are reported in Table 4, we find omissions (abacus $\rightarrow$ "I do not know"), descriptions (yoke $\rightarrow$ "holds a cow"), and semantic substitutions (knocker $\rightarrow$ "door chime"), but not phonological distortions. That is, her errors attest to word-finding difficulties-not surprising, given that some of these pictures depict rather unfamiliar objects-but do not reveal a problem in phonological processing. Similar findings were obtained from the administrations of the Boston Naming Test that were part of the followup battery (see Patient Description): No phonological errors were detected there.

We also assessed whether phonological distortions were present in more naturalistic speech 
Table 4. $R G$ 's incorrect picture naming responses

\begin{tabular}{|c|c|c|}
\hline Picture & Test & $R G$ 's naming response \\
\hline Wheelchair & BNT & $\begin{array}{l}\text { Person can't walk so has to have } \\
\text { something with wheels }\end{array}$ \\
\hline Seahorse & $\mathrm{BNT}$ & I don't know \\
\hline Escalator & BNT & Staircase in a department store \\
\hline Knocker & $\mathrm{BNT}$ & Door chime \\
\hline Compass & BNT & I don't know \\
\hline Tongs & $\mathrm{BNT}$ & Tweezers \\
\hline Yoke & $\mathrm{BNT}$ & Holds a cow \\
\hline Trellis & $\mathrm{BNT}$ & I don't know \\
\hline Palette & BNT & For painting \\
\hline Abacus & $\mathrm{BNT}$ & I don't know \\
\hline Jacket & PNT & I don't know \\
\hline Telescope & PNT & I don't know \\
\hline Screw & PNT & Nail \\
\hline Harness & PNT & I don't know \\
\hline Fly & $\mathrm{S} \& \mathrm{~V}$ & Mosquito \\
\hline
\end{tabular}

BNT = Boston Naming Test PNT $=$ Philadelphia Naming Test; $\mathrm{S} \& \mathrm{~V}=$ Snodgrass and Vanderverwart's picture set.

samples. RG was asked a series of questions that required lengthy answers, such as "How do you bake a pie? Tell me from start to finish" or "Tell me about your family." Her responses were systematically recorded and transcribed so as to analyse the content for errors. We recorded about 20 minutes of RG's speech samples. While the content of her responses was often disjointed, she demonstrated intact speech production ability and a lack of phonological errors, as can be seen from the excerpts in Table 5. Thus, in RG's speech we could not detect any of the errors that characterise the phonological impairment of aphasic patients with expressive disorders.

\section{Lexical decision}

It is possible that RG's putative phonological impairment affected speech comprehension rather than speech production. To test this, RG was assessed with an auditory lexical decision task. RG was presented with 10 words and nonwords spoken to her randomly by the experimenter and her task was to decide whether each item corresponded to a word. The nonwords were developed by changing one or two letters in familiar words (e.g., mushroom $\rightarrow$ mushrame). RG's responses were
Table 5. Samples of $R G$ 's spontaneous speech

Excerpt from RG's response to the question "Tell me about your family"

"I have one daughter who lives here in Queens...that's really my husband's daughter [from a previous marriage] and another daughter, that's Debbie, who lives a little bit further. They're both here. My mother lives here too [in Queens]. And you know my husband...he's in the other room, I don't know what he's doing though."

Excerpt from RG's response to the question "Tell me how to play tennis"

"You have to use a racquet and play with someone

else...you can go to the courts together and you hit the ball until someone misses it. My husband is very good at tennis. I don't play anymore. He tries to play with his friends."

invariably correct in this task, a result revealing seemingly intact phoneme processing in speech comprehension.

\section{Text reading}

Friedman (1996) reported two phonological dyslexic patients who experienced significantly more problems in reading functors (particles, determiners, auxiliaries, etc.) when the words were shown to the patients in a text than when shown the words in isolation. Friedman attributed these problems with functors to the patients' verbal short-term memory impairment that caused problems in maintaining phonological information in memory. Patients with a short-term memory deficit of this kind would encounter difficulties in text reading, a task especially taxing for verbal short-term memory, and particularly with functors, because these words receive little support from semantics and therefore require high activation levels to be maintained in short-term memory. Because nonwords also demand high activation levels, nonword reading might also be deficient in conditions in which verbal short-term memory is impaired. RG's verbal short-term memory is also impaired and this may (at least in part) explain her nonword reading deficit. Consistent with what was reported by Friedman, RG would have demonstrated problems with functors in text reading. 
To test this prediction, RG was asked to read three short texts, which altogether were composed of 835 words, of which 385 were functors. Only one error was recorded with functors (is $\rightarrow$ "as"), and apart from a few errors with relatively infrequent words (ecosystem, oxygen, dioxide, thoracic, processes) and, not surprisingly, with unfamiliar geographical names (Ticonderoga, Duquesne), RG read the text accurately and fluently. The data from text reading do not support the conclusion that RG's nonword reading deficit results from a verbal short-term memory impairment, as proposed by Friedman. Additional data consistent with this conclusion come from the analysis of RG's errors when reading nonwords of varying length. If a short-term memory deficit is at the basis of the problems with nonwords, one is likely to observe a length effect: Errors increase for longer nonwords (on this point see also Caramazza, Capasso, \& Miceli, 1996). But as can be seen in Table 3, length does not affect RG's error rate with nonwords. In sum, it does not seem that RG's verbal short-term memory impairment had repercussions for reading, as was proposed for other phonological dyslexic patients.

\section{Word and nonword repetition}

Nonword repetition is one of the phonological tests in which patients with phonological dyslexia are deficient (e.g., Caramazza, Miceli, \& Villa, 1986), and this was one of the findings cited in support of the claim that a phonological deficit is the source of the nonword reading impairment observed in phonological dyslexia. We tested whether RG is impaired at nonword repetition by asking her to repeat a subset of the nonwords shown earlier in the reading aloud task. In this latter task, nonwords were presented along with words; the same procedure was used for the repetition tasks, so as to have the procedures for both tasks as similar as possible. Words $(N=224)$ and nonwords $(N=390)$ were randomly pronounced by the experimenter, and $\mathrm{RG}$ was asked to repeat each one and was informed that some were not real words. If requested, the investigator repeated the item. In trials in which $\mathrm{RG}$ provided multiple responses, the last response was retained for scoring, as in the reading aloud task. RG correctly repeated $383 / 390$ (98\%) of the nonwords. Thus, there is a striking difference between RG's performance in the repetition and the reading tasks: She was far better at repeating the nonwords than she was at reading them (98\% vs. $54 \%$ correct), and in repetition (but not in reading), accuracy was comparable between nonwords and words (98\% vs. $97 \%$ correct). Notably, RG's correct responses were not confined to monosyllabic words but extended to longer two-, three-, and foursyllable nonwords, which RG almost always repeated correctly (89/90, 99\%; see data in Table 6). The latter aspect further attests to the intactness ${ }^{3}$ of $\mathrm{RG}$ 's performance in the repetition task.

\section{Rhyme production}

In this task, the experimenter said a word and RG responded by pronouncing a rhyming word. This task was quickly understood by RG, although she required the instructions to be repeated at various points throughout the task. For example, on a few trials she responded with a word that was associated with the probe word (car $\rightarrow$ "ride") or she provided a definition ( $\mathrm{arm} \rightarrow$ "can hold something"). On these trials the instructions were repeated and the item was presented again; the response that $\mathrm{RG}$ gave at this point was retained for analysis. We opted to use this procedure because it takes into account RG's problem with remembering task instructions. $\mathrm{RG}$ produced a rhyming word on $60 / 63$ of the trials

\footnotetext{
${ }^{3}$ Farah et al. (1996) pointed out that even patients with impaired phonological representations can perform well in the nonword repetition task, because the auditory support available in this task (but not in nonword reading) would help to counteract the degradation of phonological information. In support of their claim they cited the finding of JD, a patient with acquired phonolgical dyslexia, who was normal at repeating single monosyllabic nonwords but impaired at repeating three monosyllabic nonwords. Supposedly, in the latter condition the support from the auditory system was reduced. RG's performance also dropped precipitously with nonword triplets (19/30 correct; 63\%). However, this may be due to RG's severely impaired verbal short-term memory-she could not repeat more than three digits - and the same explanation may hold for patient JD, whose verbal short-term memory was also impaired.
} 
Table 6. Repetition tasks: Words and nonwords

\begin{tabular}{llcc}
\hline Length & \multicolumn{1}{c}{ Examples } & $N$ & $N$ (\%) Correct repetitions \\
\hline Two syllables & mibgus, shomble, thapel & 30 & $30(100 \%)$ \\
Three syllables & mactory, jumbustion, closterman & 30 & $30(100 \%)$ \\
Four syllables & malligraphy, rociferate, karatmensin & 30 & $29(96 \%)$ \\
\hline
\end{tabular}

(95\%), an exceedingly strong performance if we consider her tendency to provide other forms of responses. Her errors consisted of two semantically related responses (search $\rightarrow$ "seek... flashlight"; horse $\rightarrow$ "to be quiet"), and one phonologically related response (pine $\rightarrow$ "pail, stein"). Errors of this sort are more likely to reflect a problem in following instructions rather than a frank phonological impairment.

\section{Rhyme identification}

Presented with pairs of spoken words, RG was asked to indicate whether the words rhyme (as in pair-bear) or do not rhyme (as in pair-gain). Fifteen words were presented twice, once with a rhyming word and once with a nonrhyming word. Pairs were controlled for orthography, in such a way that the rhyming and the nonrhyming pairs shared a comparable number of letters (rhyming pairs shared an average of 2.2 letters and nonrhyming pairs shared an average of 2.3 letters per word). This control of orthography rules out the possibility that RG was correct because she responded by accessing orthographic information. All the pairs (30/30) were correctly discriminated by RG.

\section{Same-onset words}

Various phonological tasks require the manipulation of a word's phonemes, as in the stripping task of Patterson and Marcel (1992), in which participants repeat the remainder of the syllable once the onset is deleted (e.g., "at" for cat). Because these tasks involved instructions that RG clearly failed to comprehend, we opted for a simpler task, which required $\mathrm{RG}$ to produce a word that began with the same phoneme as the word pronounced by the experimenter. The instructions included the following: "If I say the word baby, I want you to tell me a word that begins with the first sound, which in this case is b. For example, you could say boy, bed, basket." RG performed well on this task: 35/36 (97\%) correct responses. The only error occurred with the word sun/son: she responded "door." For most of the items she was able to produce more than one word beginning with the same phoneme, as in shot $\rightarrow$ "sugar, shore" or gin $\rightarrow$ "juggle, gym." As is evident from these examples, RG's responses were not driven by orthography, and so she provided words with onset consonants that were phonologically but not orthographically identical to the probe, as gin-juggle or shot-sugar.

\section{Discontinued phonological tests}

Other tests used in previous studies were discontinued because RG failed to comprehend the instructions or could not keep in mind the various alternatives spoken by the experimenter. For each of these tests the experimenter presented the instructions several times and the patient was corrected consistently following each incorrect response. Before being discontinued, a task was represented in a second testing session. The discontinued tasks all involved the presentation of verbal material and include (1) syllable counting, (2) phoneme stripping (cat $\rightarrow$ "at"; Patterson \& Marcel, 1992), (3) onset phoneme identification ("say the first sound of the word lamp"), (4) phoneme blending (identifying a monosyllabic word from its onset and rhyme, as in $b$, at $\rightarrow$ "bat"; Derouesné \& Beauvois, 1985), and (5) nonword completion (e.g., the experimenter said the nonword "shid"; RG was shown the written letter string $s h \_d$ and was asked to pronounce the missing phoneme, /i/; Derouesné \& Beauvois, 1985). It was evident that the patient could not understand the 
instructions, because she offered responses that did not fit the task. For example, when she was presented with "b... at" she responded "Dracula" rather than bat. ${ }^{4}$ Evidence that RG could not understand the instructions could also be seen when she orally spelled a word instead of counting its syllables.

\section{GENERAL DISCUSSION}

$\mathrm{RG}$, the patient reported in this paper, presented with moderate $\mathrm{pAD}$ with a clear-cut dissociation in reading. Various lines of evidence showed that RG's word reading was intact. In standardised reading tasks her scores were well within the normal range. Her few errors (only 43 out of 1404 words; $3 \%)$ were confined to infrequent words like scion, imbroglio, or factitious. Remarkably, she was able to read rarely encountered irregular words like façade, catastrophe, and regime. However, nonword reading was markedly impaired, as shown by her correct rates on a number of lists, which were all below 69\%. RG's failure with nonwords cannot be attributed to the use of mixed lists composed of words and nonwords. In fact, accuracy and error distribution were comparable between mixed lists and lists only composed of nonwords. In short, RG represents a "pure" case of phonological dyslexia. In contrast to what has been observed in the majority of cases of phonological dyslexia, phonological processing appears to be spared in RG. Her responses were invariably correct in tasks designed to assess the intactness of her phonological processing, including repeating words and nonwords, producing a rhyming word or a word with a given onset phoneme, and recognising whether words rhymed. Nor were anomalies suggestive of a phonological impairment observed in RG's speech production and comprehension. In short, RG presents with a dissociation between (impaired) nonword reading and (preserved) phonological processing, a dissociation that was previously reported in only two other patients with acquired phonological dyslexia-patients LB (Derouesné \& Beauvois, 1985) and patient RR (Bisiacchi et al., 1989).

RG's dementia severely limits the type of phonological tasks that may be administered to the patient. As a result, we obtained data from only a fraction of the host of tasks that neuropsychologists have developed to assess phonological processing. One could be legitimately concerned that the phonological tasks completed by RG were not subtle enough to detect a phonological impairment. In other words, RG's apparent good performance is an artifact of task selection rather than reflecting a genuine preservation of phonological processing. There are good reasons for disregarding these concerns. Let us consider repetition of single orally presented nonwords and rhyme production, two of the phonological tasks in which RG performed well. Nonword repetition was compromised for three of the five patients with acquired phonological dyslexia described by Berndt et al. (1996) and for patient CJ described by Patterson (2000). Moreover, Patterson reported that the rhyme production task had to be discontinued with CJ because it was too arduous for the patient. These data show that RG's data were certainly not obtained from tasks that fail to reveal a phonological deficit. Of course, it could be argued that there is a problem with the material specifically selected for our tasks: We only picked "easy" items. But this is also not true, as shown by the data of LM, a patient with phonological dyslexia resulting from a CVA (Teich \& Miozzo, 2002). LM's reading of nonwords was more severely impaired than his reading of words (1/10, $10 \%$ vs. $143 / 161$, $89 \%)$. The same phonological tasks used for RG were administered to LM. Although able to detect whether two orally presented words rhymed $(100 \%$ correct) or to repeat nonwords (95\% correct), LM produced a rhyming word only on $77 \%$ of the trials.

\footnotetext{
${ }^{4}$ Responding with the associated words "Dracula" suggests that RG recognised that b+at corresponds to the word bat. A few responses of this type were noticed in the discontinued tasks. They give us some hints that RG's difficulties with these tasks was not due to a phonological impairment but rather the result of her focusing on the responses she felt were expected for the task in hand.
} 
Thus, LM's data do not lend support to the argument that RG's performance reflects an improper material selection. Finally, one could speculate that the tasks that RG was not able to complete could have revealed a phonological deficit in the patient. However this speculation does not seem reasonable either. In fact, some patients with acquired phonological dyslexia did not have problems in the tasks that RG failed to understand. For example, patient CJ (Patterson, 2000) performed reasonably well (93\% correct) when asked to indicate the number of syllables of orally presented words. Moreover, LM was invariably correct in providing the initial sound of orally presented words (20/20 correct).

Obviously, the fact that RG cannot accomplish some of the phonological tests prevents us from ruling out a phonological deficit with absolute certainty. The conclusions that we can draw from RG's data are more circumscribed: A reading impairment that is selective for nonwords can be observed even in the absence of problems in phoneme detection, repeating nonwords, producing rhyming words, and it can be dissociated from phonological distortions in speech production or confusions between phonologically similar words in speech comprehension. Yet, this conclusion has relevant implications for current reading models, in particular for models that do not postulate mechanisms specific for nonword processing but rather assume shared mechanisms for words and nonwords (e.g., Farah et al., 1996; Harm \& Seidenberg, 1999; Plaut et al., 1996; Seidenberg \& McClelland, 1989). The explanation of phonological dyslexia proposed within this type of model is that a phonological impairment is at the root of this deficit, an explanation we referred to as the phonological impairment account. The data obtained from RG severely constrain the nature of the phonological impairment responsible for the nonword reading deficit. It cannot be a deficit with widespread consequences for speech production and comprehension or for every phonological task, in that no anomalies were detected in RG's speech comprehension and production and her performance was seemingly preserved in all the phonological tasks that she was able to understand. The consequences of this deficit must be far more selective and should only affect nonword reading and (at least theoretically) some phonological tasks. Defining what makes these tasks more vulnerable than those in which RG performed well is the challenge raised by RG's data.

Unfortunately, current theories remain vague about which phonological mechanisms are damaged in phonological dyslexia, but without specifying this point the phonological impairment account remains more a logical possibility than a suitable explanation of nonword reading deficits. One exception is the hypothesis advanced by Friedman (1996), which specifies the locus of the phonological impairment-verbal short-term memory - and makes precise predictions about the type of deficit associated with this impairmentproblems with functor words in text reading. Although at the time of our investigation her verbal short-term memory was impaired, RG did not encounter problems with functors in text reading, a result that allows us to reject the hypothesis that a verbal short-term memory deficit is the source of RG's nonword reading impairment (but see the Results section for other data that exclude a link between verbal short-term memory deficit and nonword reading deficit). So-called triangle reading models (e.g., Harm \& Seidenberg, 1999; Plaut et al., 1996), which provide the theoretical background to the phonological impairment hypothesis, are sufficiently detailed to allow computer implementations and simulations of the effects of damage to the different components of the model. In the past, the results of these simulations were used to test specific interpretations of the various forms of acquired reading deficits observed in neuropsychology (e.g., Harm \& Seidenberg, 1999; Plaut \& Shallice, 1993). Whether and how it is possible to reproduce the pattern of clear-cut dissociations documented in RG by damaging the phonological mechanisms would then represent a critical test for triangle models of reading.

Farah and collaborators also subscribe to the phonological deficit hypothesis on the rationale, based on an evolutionary argument, that there are no brain areas specifically devoted to nonword reading or to reading in general (Farah, 1992; Farah 
et al., 1996). Phonological processing, an evolutionarily older cognitive function partially under genetic control, has dedicated brain regions and it is the damage to these regions that supposedly determines phonological dyslexia. RG's good performance in several phonological tasks provides evidence that is prima facie problematic for this account. But it is also on theoretical grounds that an account rooted on evolutionary arguments can be questioned. Even if one agrees that genetically determined brain areas do not exist for reading, it remains highly feasible that brain regions are dedicated to reading. Because of the specific functional demands imposed by reading, which involves the integration of visual, semantic, and linguistic processes, the development of readingspecific brain areas could be an optimal solution, both from a functional and an anatomical perspective. The pre-existing organisation of visual, semantic, and linguistic areas would not only constrain where in the brain the reading areas will be located-most likely in a region that allows an efficient integration of visual, semantic, and linguistic information-but it would also determine a consistent recruitment of the same areas across individuals. In this scenario, reading deficits, including phonological dyslexia, can result from damage to brain areas specific to reading.

If RG's data are challenging for reading models that appeal to the phonological impairment account, they are, on the other hand, naturally consistent with dual-route models of reading. Because phonological dyslexia is not attributed to a phonological impairment within these latter models, it would not be inconceivable to observe selective nonword reading deficits without phonological impairment. RG's deficit can be accounted for in terms of damage affecting the nonlexical route but sparing the lexical route. As a consequence of this type of damage, word reading can remain normal even if nonword reading is impaired, as indeed we have observed in RG. Of course the challenge raised by patients like $R G$ is whether dual-route models can provide a comprehensive account of the various aspects of their reading deficits. Proponents of the dual-route model agree that at least three sets of processes are implicated in nonword reading (e.g., see Coltheart, 1985; Derouesné \& Beauvois, 1985; Newcombe \& Marshall, 1985; see also Shallice, 1988). A first set of processes leads to the identification of the graphemes comprising the stimuli. Graphemes are then converted into their corresponding phonemes by means of transcoding processes that allow readers to derive the orthography-phonology mappings specific to the language. A final set of processes, phonological in nature, is responsible for transforming the phoneme sequence into an articulatory programme. Not all of these processes are primarily dedicated to nonword reading; grapheme segmentation and phonological processes are also implicated in word reading. In light of the fact that RG performed well in reading familiar words as well as in phonological tasks, it seems unlikely that her nonword reading deficit originated from damage at the level of grapheme segmentation and/or phonological processes. More probably her deficit stemmed from a problem at the level of grapheme-to-phoneme mapping. Can this hypothesis account for other features of RG's nonword reading impairment? At stake is whether it can explain why (1) RG correctly read the majority of the nonwords and (2) her errors mostly consisted of lexicalisations.

The fact that RG could successfully read a fair proportion of nonwords indicates, at a minimum, that grapheme-to-phoneme mapping processing was partially functioning. We have further observed that $R G$ responded significantly more accurately to nonwords formed by graphemes with highly predictable pronunciations than to nonwords composed of graphemes with lower probability of correspondence to any single phoneme. Perhaps the simplest way to account for this discrepancy is by assuming that phonemes are less activated by the grapheme-to-phoneme conversion mechanisms than in normal conditions. When activation converges on a single phoneme set, as is likely to occur with nonwords composed of highly predictable graphemes, there are no other viable responses, and it might be possible to correctly produce the word. In contrast, when graphemes have less predictable phoneme correspondents, more than one phoneme set is activated, and since the correct 
phonemes are weakly activated, it is very possible to select the wrong response. Further evidence showing that the predictability of phonological transcoding affected RG's responses can be accrued from a comparison between consonants and vowels. In English, vowels are typically less predictable than consonants-compare, for example, the grapheme $i$, which can be pronounced in several ways, and the grapheme $b$, which is almost invariably pronounced as $/ \mathrm{b} /$. Given this contrast, $\mathrm{RG}$ is also expected to perform less accurately with vowels than consonants in nonword reading. We tested this prediction by examining nonword responses in which a single phoneme was incorrectly realised, as in the case of joon $\rightarrow$ "zoon" or kun $\rightarrow$ "kune" (rhyming with June). (Lexicalisations were excluded from this analysis since the selection of a given word response might not directly depend on the incorrect functioning of the grapheme-tophoneme mapping mechanisms.) RG's singlephoneme errors were far more frequent with vowels $(42 / 54 ; 78 \%)$ than consonants (12/54; 23\%), despite the fact that the nonwords contained more consonants than vowels. Thus, we have more than one line of evidence indicating that RG was (relatively) able to derive the pronunciation of predictable graphemes, which (in part) explains why RG successfully read several nonwords.

Recent versions of dual-route models (e.g., the cascaded model proposed by Coltheart, Rastle, Perry, Ziegler, \& Langdon, 2001) assume that both lexical and nonlexical routes activate phonological forms, an assumption that also holds for nonword reading. It is hypothesised that when a nonword (e.g., jeap) is presented, orthographically similar words (e.g., leap) are also activated, and their activation increases as a function of the orthographic overlap. Orthographically similar words also activate their corresponding phonological forms via the lexical route. In normal conditions, the phonological forms activated by familiar words are not selected-instead, the forms activated by the nonlexical route are chosen. However, if the nonlexical route is impaired and yields weak responses, whereas the lexical route functions normally, phonological forms activated by the lexical routes are likely to be selected, giving rise to the lexicalisation errors that we have observed in RG. In the context of this explanation, it is worth considering that RG's lexicalisations tended to be more common with nonwords that were visually similar to word sets with consistent pronunciation (e.g., leap, heap, reap, etc.; consistent neighbours) relative to word sets with inconsistent pronunciation (as in bear/fear; inconsistent neighbours). To account for this distribution of RG's lexicalisations, one could propose that words with consistent neighbours are more likely to be (incorrectly) selected for at least two reasons. One is that a single phonological form is strongly activated by the lexical route if the word is from a consistent neighbourhood-note that multiple phonological forms are activated for nonwords with inconsistent neighbours. The other is that words with consistent pronunciation receive further activation from the partially functioning nonlexical route-note that within inconsistent neighbourhoods, some of the words have irregular spellings and therefore would not be activated by the sublexical route.

In conclusion, in this paper we addressed the question of whether, in patient $\mathrm{RG}$, a deficit for nonword reading is dissociable from a phonological deficit. The fact that a number of phonological tasks could not be administered to RG prevents us from providing a definitive answer to this question. Nevertheless, RG's remarkably intact performance on a number of tasks specifically designed to detect the presence of phonological impairments clearly defines the tasks in which performance can remain intact in patients with reading deficits confined to nonwords.

Manuscript received 22 January 2003

Revised manuscript received 5 August 2003

Revised manuscript accepted 5 August 2003

\section{REFERENCES}

Badecker, W., Hillis, A. E., \& Caramazza, A. (1990). Lexical morphology and its role in the writing process: Evidence from a case of acquired dysgraphia. Cognition, 35, 205-243.

Berndt, R. S., Haendiges, A. N., Mitchum, C. C., \& Wayland, S.C. (1996). An investigation of nonlexical 
reading impairments. Cognitive Neuropsychology, 13, 763-801.

Bisiacchi, P. S., Cipolotti, L., \& Denes, G. (1989). Impairment in processing meaningless verbal material in several modalities: The relationship between shortterm memory and phonological skills. Quarterly Journal of Experimental Psychology, 41A, 293-319.

Blumstein, S. E. (Ed.). (1981). Neurolinguistic disorders: Language-brain relationships. New York: John Wiley.

Butters, N., Salmon, D. P., Cullum, C. M., Cairns, P., Troster, A. I., Jacobs, D., et al. (1988). Differentiation of amnesic and demented patients with the Wechsler Memory Scale-Revised. The Clinical Neuropsychologist, 2, 133-144.

Caramazza, A., Capasso, R., \& Miceli, G. (1996). The role of the graphemic buffer in reading. Cognitive Neuropsychology, 13, 673-698.

Caramazza, A., Miceli, G., \& Villa, G. (1986). The role of the (output) phonological buffer in reading, writing, and repetition. Cognitive Neuropsychology, 3, 37-76.

Coltheart, M. (1985). Cognitive neuropsychology and the study of reading. In M. I. Posner \& O. S. M. Marin (Eds.), Attention and performance XI. Hillsdale, NJ: Lawrence Erlbaum Associates Inc.

Coltheart, M. (1996). Phonological dyslexia: Past and future issues. Cognitive Neuropsychology, 13, 749-762.

Coltheart, M., Besner, D., Jonasson, J.T., \& Davelaar, E. (1979). Phonological encoding in the lexical decision task. Quarterly Journal of Experimental Psychology, 31, 489-507.

Coltheart, M., Curtis, B., Atkins, P., \& Haller, M. (1993). Models of reading aloud: Dual-route and parallel-distributed processing approaches. Psychological Review, 100, 589-608.

Coltheart, M., Patterson, K., \& Marshall, J. C. (Eds.). (1987). Deep dyslexia (2nd ed.). London: Routledge \& Kegan Paul.

Coltheart, M., Rastle, K., Perry, C., Ziegler, J., \& Langdon, R. (2001). DRC: A dual route cascaded model of visual word recognition and reading aloud. Psychological Review, 108, 204-256.

Cummings, J. L., Houlihan, J. P., \& Hill, M. A. (1986). The pattern of reading deterioration in dementia of the Alzheimer type: Observations and implications. Brain and Language, 29, 315-23.

Derouesné, J., \& Beauvois, M. F. (1985). The "phonemic" state in the non-lexical reading process: Evidence from a case of phonological alexia. In K. Patterson, J. C. Marshall, \& M. Coltheart (Eds.), Surface dyslexia (pp. 399-457). Hove, UK: Lawrence Erlbaum Associates Ltd.
Farah, M. J. (1992). Visual agnosia. Cambridge, MA: Bradford Books.

Farah, M., Stowe, R. M., \& Levinson, K. L. (1996). Phonological dyslexia: Loss of a reading-specific component of cognitive architecture? Cognitive Neuropsychology, 13, 849-868.

Francis, N. W., \& Kucera, H. (1982). Frequency analysis of English usage. Boston, MA: Houghton Mifflin.

Friedman, R. B. (1996). Phonological text alexia: Poor pseudoword reading plus difficulty in reading functors and affixes in text. Cognitive Neuropsychology, 13, 869-885.

Friedman, R. B., Ferguson, S., \& Robinson, S. (1992). Dissociation of mechanisms of reading in Alzheimer's disease. Brain and Language, 43, 400-413.

Fromm, D., Holland, A. L., Nebes, R. D., \& Oakley, M. A. (1991). A longitudinal study of word-reading ability in Alzheimer's disease: Evidence from the National Adult Reading Test. Cortex, 27, 367-376.

Funnell, E. (2000). Case studies in the neuropsychology of reading. Hove, UK: Psychology Press.

Glushko, R. J. (1979). The organization and activation of orthographic knowledge in reading aloud. Journal of Experimental Psychology: Human Perception and Performance, 5, 674-691.

Goodman, R., \& Caramazza, A. (1986). The Johns Hopkins Dyslexia Battery. Baltimore, MD: Johns Hopkins University.

Graham, K. S., Hodges, J. R., \& Patterson, K. (1994). The relationship between comprehension and oral reading in progressive fluent aphasia. Neuropsychologia, 32, 299-316.

Grober, E., \& Sliwinski, M. J. (1991). Dual-task performance in demented and nondemented elderly. Journal of Clinical and Experimental Neuropsychology, 13, 667-676.

Harm, M. W., \& Seidenberg, M. S. (1999). Phonology, reading acquisition, and dyslexia, insights from connectionist models. Psychological Review, 106, 491-528.

Harm, M. W., \& Seidenberg, M. S. (2001). Are there orthographic impairments in phonological dyslexia? Cognitive Neuropsychology, 18, 71-92.

Jastak, S., \& Wilkinson, G. S. (1984). Wide Range Achievement Test-Revised. Wilmington, DE: Jastak Assessment Systems.

Kaplan, E. F., Goodglass, H., \& Weintraub, S. (1983). The Boston Naming Test (2nd ed.). Philadelphia: Lea \& Febiger.

Kay, J., \& Patterson, K. E. (1985). Routes to meaning in surface dyslexia. In K. E. Patterson, J. C. Marshall, \& 
M. Coltheart (Eds.), Surface dyslexia (pp. 79-104). Hove, UK: Lawrence Erlbaum Associates Ltd.

Marshall, J. C., \& Newcombe, F. (1973). Patterns of paralexia: A psycholinguistic approach. Journal of Psycholinguistic Research, 2, 175-199.

Mayeux, R., Stern, Y., Rosen, J., \& Leventhal, J. (1981). Depression, intellectual impairment, and Parkinson disease. Neurology, 31, 645-50.

Miozzo, M., \&Barnes, J. (2002). Semantic discrimination test. Unpublished test.

Monsch, A. U., Bondi, M. W., Butters, N., Salmon, D. P., Katzman, R., \& Thal, L. J. (1992). Comparisons of verbal fluency tasks in the detection of dementia of the Alzheimer type. Archives of Neurology, 49, 1253-1258.

Newcombe, F., \& Marshall, J. C. (1985). Reading and writing by letter sounds. In K. E. Patterson, J. C. Marshall, \& M. Coltheart (Eds.), Surface dyslexia. Hove, UK: Lawrence Erlbaum Associates Ltd.

Patterson, K. (2000). Phonological alexia: The case of the singing detective. In E. Funnell (Ed.), Case studies in the neuropsychology of reading (pp. 57-83). Hove, UK: Lawrence Erlbaum Associates Ltd.

Patterson, K., \&Lambon Ralph, M. A. (1999). Selective disorders of reading? Cognitive Neuroscience, 9, 235239.

Patterson, K., \& Marcel, A. J. (1992). Phonological ALEXIA or PHONOLOGICAL alexia? In J. Alegria, D. Holender, J. Junca de Morais, \& M. Radeau (Eds.), Analytic approaches to human cognition (pp. 259-274). New York: Elsevier.

Plaut, D. C., McClelland, J. L., Seidenberg, M. S., \& Patterson, K. (1996). Understanding normal and impaired word reading: Computational principles in quasi-regular domains. Psychological Review, 103, 56-115.

Plaut, D. C., \& Shallice, T. (1993). Deep dyslexia. A study of connectionist neuropsychology. Cognitive Neuropsychology, 10, 377-500.
Rapp, B., Folk, J. R., \& Tainturier, M. J. (2001). Word reading. In B. Rapp (Ed.), The handbook of cognitive neuropsychology. Philadelphia: Psychology Press.

Riddoch, M. J., \& Humphreys, G. W. (1993). BORB Birmingham Object Recognition Battery. Hove, UK: Lawrence Erlbaum Associates Ltd.

Roach, S., Schwartz, M. F., Martin, N., Grewal, R. S., \& Brecher, A. (1996). The Philadelphia Naming Test: Scoring and rationale. Clinical Aphasiology, 24, 121133.

Seidenberg, M. S., \& McClelland J. L. (1989). A distributed, developmental model of word recognition and naming. Psychological Review, 96, 523-68.

Shallice, T., (1998). From neuropsychology to mental structure. Cambridge, UK: Cambridge University Press.

Shallice, T., Warrington, E., \& McCarthy, R. (1983). Reading without semantics. Quarterly Journal of Experimental Psychology, 35A, 111-138.

Snodgrass, J. G., \& Vanderwart, M. (1980). A standardized set of 260 pictures: Norms for name agreement, image agreement, familiarity and visual complexity. Journal of Experimental Psychology: Human Learning and Memory, 6, 174-215.

Teich, A. W., \& Miozzo, M. (2002). The role of the graphemic buffer. Cognitive Neuroscience meeting, San Francisco, USA.

Venezky, R. L. (1970). The structure of English orthography. The Hague: Mouton.

Welsh, K., Butters, N., Hughes, J., Mohs, R., \& Heyman, A. (1991). Detection of abnormal memory decline in mild cases of Alzheimer's disease using CERAD neuropsychological measures. Archives of Neurology, 48, 278-281. 
Copyright of Cognitive Neuropsychology is the property of Psychology Press (T\&F) and its content may not be copied or emailed to multiple sites or posted to a listserv without the copyright holder's express written permission. However, users may print, download, or email articles for individual use. 